Portland State University

PDXScholar

\title{
"We're More Than a Daycare": Reported Roles and Settings for Early Childhood Professionals and Implications for Professionalizing the Field
}

\author{
Rachel E. Schachter \\ University of Nebraska \\ Qingyu Jiang \\ University of Nebraska \\ Shayne B. Piasta \\ The Ohio State University \\ Erin E. Flynn \\ Portland State University, flynn2@pdx.edu
}

Follow this and additional works at: https://pdxscholar.library.pdx.edu/socwork_fac

Part of the Social Work Commons

Let us know how access to this document benefits you.

\section{Citation Details}

Schachter, R. E., Jiang, Q., Piasta, S. B., \& Flynn, E. E. (2021). [Post-print version] "We're more than a daycare": Reported roles and settings for early childhood professionals and implications for professionalizing the field. Early Childhood Education Journal. https://doi.org/10.1007/ s10643-021-01252-8

This Post-Print is brought to you for free and open access. It has been accepted for inclusion in School of Social Work Faculty Publications and Presentations by an authorized administrator of PDXScholar. Please contact us if we can make this document more accessible: pdxscholar@pdx.edu. 
Running Head: EC ROLES AND SETTINGS

"We're more than a daycare:" Reported roles and settings for early childhood professionals and implications for professionalizing the field

\author{
Rachel E. Shachter \\ University of Nebraska \\ Qingyu Jiang \\ University of Nebraska \\ Shayne B. Piasta \\ Ohio State University \\ Erin E. Flynn \\ Portland State University
}

This is the Accepted Version of an article published in the Early Childhood Education Journal.

To cite: Schachter, R.E., Jiang, Q., Piasta, S.B., Flynn, E.E. (2021). "We're more than a daycare": Reported roles and settings for early childhood professionals and implications for professionalizing the field. Early Childhood Educ Journal.

https://doi.org/10.1007/s10643-021-01252-8 


\begin{abstract}
In the US, recent efforts have focused on professionalizing the field of early childhood. One way to indicate professionalism is through the terms used to describe both the field and the workers. However, few have examined how practitioners or researchers describe early childhood professionals' work. Using multiple data sources and analytic strategies, we examined the ways that those working with young children described their role and setting, as well as how these were described in research and practitioner journals. "Teacher" was the preferred term for both journals and professionals, and terms for setting reflected traditional K-12 school structures. Professionals linked these terms to the idea that early childhood education was teaching and preparing children for formal schooling. Many contrasted their work with daycare and babysitting, noting that planning, curriculum use, expertise, program quality, funding mechanisms, professionalism, and early childhood as an important developmental period all contributed to their roles as teachers in preschool settings. Implications are discussed.
\end{abstract}

Keywords: early childhood, professionalism, professional's perspectives 


\section{"We're more than a daycare:" Reported roles and settings for early childhood professionals and implications for professionalizing the field}

Early childhood (EC) education in the United States of America (US) has received growing attention with a focus on improving instruction and developing children's kindergarten readiness skills. Increasingly, EC professionals take a more active teaching role reminiscent of the instruction employed in K-12 settings (Author, 2017; Bassok et al., 2017). As such, it is not clear how this might shift not just what happens in EC sites, but how EC professionals view their work, and in turn, themselves. Recent calls have argued for the continuing professionalization of the early childhood workforce (Whitebook et al. 2009; Workgroup on the Early Childhood Workforce and Professional Development et al., 2016). One way to encourage a more consistent conception of a profession is through the labels used to describe both the field of EC and those working within the field (Harwood et al., 2013). Specifically, the ways that researchers and organizations position the work of EC directly influences how those who work with young children are perceived (Boyd, 2013; Jónsdóttir \& Coleman, 2014; Shpancer et al., 2008). Public perception of EC professionals in the US has tended to be more negative with EC professionals typically not accorded the same status and value as their counterparts who work with older children (Whitebook et al., 2014). Thus, the EC workforce stands at the complex intersection of a changing field, with an increased focus on professionalization and an ongoing need to improve public perception of the EC workforce including paying professionals a wage in keeping with carrying out worthy work (Whitebook et al., 2014).

As EC professionals are the ones doing the work in classrooms, their views regarding their work and their role matter. For professionalization to be something more than a top-down process driven by researchers or policymakers, the perspectives of the EC workforce must be 
centered. Sisson and Kroeger (2017) argue that EC professionals are in constant dialog between their own views of their work and those in their environment. Thus, how they reconcile their roles with views coming from the field are important for understanding this process of professionalism. A critical component of this is then in the labeling of these roles by the professional and others through ongoing discourse (Hardwood et al., 2013; Author, 2020; Sisson, 2016).

How EC professionals view themselves and where they work is also shaped by the complex context of EC as well as the broader cultural milieu of the US, a country that has not made universal access to EC available in the same way as other economically developed countries (OECD, 2017). It may be that the EC workforce in the US faces unique challenges in defining and naming the nature of their work given the patchwork landscape of mixed market, mixed delivery EC along with uneven investment and access, as we describe below. The purpose of this study is to examine how the extant literature as well as EC professionals working in center-based settings label the settings and roles for working with children 3-5 in the US. Next, we discuss the US EC context and then turn to current research regarding professionals' perspectives regarding their roles and settings.

\section{EC Programming in the US}

The current US EC system includes multiple types of settings and funding mechanisms. Although EC is typically defined as ages 0-8 (National Association for the Education of Young Children [NAEYC], 2009), in the US, the systems for children 0-5 are often different than those for children 6-8. The latter traditionally attend free, state-run public-school settings, whereas children ages 0-5 can be in a variety of EC settings (Institute of Medicine \& National Research Council [IOM \& NRC], 2012; Whitebook et al., 2018) including federally-funded Head Start 
settings, state-funded prekindergarten settings, for profit or non-profit settings (paid largely by families out of pocket), and hybrid versions of these settings (e.g., partially subsidized statefunded prekindergarten). Furthermore, there are often distinct differences between systems for infants and toddlers (0-3) and children ages 3-5 in provision of services, policy emphases, and requirements for professionalism (Jessen-Howard et al., 2018; Madill et al., 2016). In this study, we focus on those professionals working with 3-5 year old children as this has been the age targeted the most in recent efforts to enhance quality of practice and professionalize the field (Barnett et al., 2016; Jónsdóttir \& Coleman, 2014; Quality Compendium, 2019).

Although EC programming in the US has received growing recognition for its role in supporting children's school readiness (Barnett et al., 2016; Markowitz et al., 2018), EC programming for 3-5 year olds is traditionally viewed as less prestigious than formal $\mathrm{K}-12$ schooling (Whitebook et al., 2014). This is evidenced by lack of consistent public funding for EC programming except for families experiencing extreme poverty (e.g., Head Start) and variability in the credentials required of EC professionals (IOM \& NRC, 2012). Although those working as the lead EC professional in Head Start or state-funded prekindergarten classrooms are often required to hold a Bachelor's degree in an education or EC-related field, those working in private settings or serving as assistants are not required to hold such degrees (IOM \& NRC, 2012; Whitebook et al., 2018). Depending on the professionals' setting, differing values may be placed on the knowledge, expertise, and work of these individuals. Furthermore, EC professionals continue to be paid at lower rates than other teachers with little policy focus on wage increases (Whitebook et al., 2014).

\section{Variability in Public Discourses about US EC Professionals}

Diversity within the US EC workforce has resulted in a variety of terms across 
organizations and documents that are used to refer to EC professionals and settings serving 3-5 year olds, both at the state and national levels. Labels for professionals include terms such as “caregiver” (MDHHS, 2019), “educator” (CDE, 2011; NYS, 2017), “professional” (NDE, 2013; ODE, 2015), "provider" (Child Care Aware, 2019; MDE, 2019; NDHHS, 2021), and "teacher" (Head Start Early Childhood Learning \& Knowledge Center, 2019; NAEYC, 2009). Similarly, multiple labels for programs are used, including “childcare” (For Our Babies, 2019; MDHHS, 2019; NDHHS, 2021; ODE, 2015), “daycare” (KDHE, 2019), and "preschool” (CDE, 2011; NAEYC, 2009). This range of terms reflects varying roles and potential practices of EC professionals and settings, which all position professionals differently in their work.

Although the terms or labels are visible within these guiding documents, how researcher and practitioner articles position EC settings and professionals is less clear. The way that professionals are perceived has implications for research and professional development. For instance, positioning EC as professionals matters for the types of professional learning they are offered, what types of training they receive, and what preexisting knowledge is valued (Cox et al., 2015; Author, 2019). These views may support or undermine views that professionals hold of themselves and their work and inform how they interact with young children in EC settings.

\section{Limited Understanding of EC Professionals' Perspectives}

Researchers have begun to examine EC professionals' perceptions of their work with studies conducted in Australia (MacFarlane \& Lewis, 2004; Sims, 2014), Canada (Harwood et al., 2013), Greece (Rentzou, 2019), Iceland (Einarsdóttir, 2003; Jónsdóttir \& Coleman, 2014), and the US (Shpancer et al., 2008) - each within its own unique EC context. Despite contextual differences, some commonalities can be observed. Most participants across these studies discussed the complexity and multifaceted nature of their role, identifying EC programming as 
being both teaching and caregiving (Einarsdóttir, 2003; Harwood et al., 2013). Importantly, in this research, professionals were very clear in identifying that their work was more than babysitting and noted the important role that they played in facilitating children's learning (Einarsdóttir, 2003; Shpancer et al., 2008). This indicates a shift to a greater emphasis on the types of learning happening in EC. Rather than focusing on EC as solely caregiving, the teaching role has become more intermingled in EC professionals' perceptions of their work, with more reporting that they do both teaching and caregiving (MacFarlane \& Lewis, 2004; Sim, 2014).

In the US specifically, some researchers have examined identity and professionals' perceptions of their roles. For example, Scherr and Johnson (2019) found that three professionals working in public school settings were highly influenced by negative discourses around them which ultimately influenced their professional practice, driving them towards what they deemed as less developmentally appropriate practice but closer to K-12 instruction. Similarly, Sisson and Kroeger (2017), using a qualitative approach found that five professionals struggled with reconciling these types of discourses which ultimately led to more focus on academics and teaching in their practice. These studies provide important insight into perceptions of roles, yet like much of the literature on this topic, rely solely on interviews and focus groups to understand professionals' views (Einarsdóttir, 2003; Harwood et al., 2013; Jónsdóttir \& Coleman, 2014). Such methods are essential for deeply understanding perceptions but limit generalization of findings due to small sample sizes.

\section{Present Study}

Overall, there is a lack of clarity regarding the terminology used to refer to EC professionals in the US. Critically, there is a gap in understanding how the professionals themselves refer to their roles. Yet these labels matter for understanding the ongoing positioning 
and professionalization of the field and discourses across professionals, researchers, and policymakers (Author, 2020; Hardwood et al., 2015). The purpose of this study was to broadly investigate, How do multiple informants label and describe the roles and places for working with children ages 3-5? We collected multiple data sources to address the following questions:

1. How are those working with children ages 3-5 and the places where that work occurs labeled in research and practitioner journals?

2. How does this align with the way that those in the field working with 3-5 year old children label and describe their role and place of work?

\section{Method}

We used a sequential mixed method design (Tashakkori \& Teddlie, 2003). To address our research questions, we collected data sequentially from quantitative and qualitative sources in multiple phases (Sandelowski, 2000) to address our research questions. In Phase 1, we conducted a content analysis (Hsieh \& Shannon, 2005) of research and practitioner journals to understand how the literature used terms for EC professionals and settings (RQ1). In Phase 2 we conducted interviews with those working in EC settings to understand their perspectives (RQ2). Finally, in Phase 3 we extended our interview findings to a larger sample of EC professionals by collecting data via a survey (RQ2). Both Phase 2 and Phase 3 data were collected as part of a broader project examining EC professionals' practice. In this study we worked with communitybased non-profit organizations to recruit teachers residing in three states across the Midwest and the Southeast. Next, we describe our research methods highlighting the different phases and data collection relevant to this specific study.

\section{Participants}

There were no research participants in Phase 1. Demographic information for participants 
in Phase $2(n=20)$ and Phase $3(n=112)$ are presented in Table 1. Across both phases of the study, participants represented a diversity of characteristics and background experiences typical of the US EC workforce (IOM \& NRC, 2012; Whitebook et al., 2018). Participants also worked in a variety of settings typical of those available in the US, including Head Start, public prekindergarten, a University-affiliated preschool, and private programs. Given this variation, we expected responses that reflected the range of perspectives held by the EC workforce in the US.

\section{Data Collection}

Phase 1. We collected data on the use of terminology in research and practitioner journals through purposive sampling within a systematic review framework (Benoot et al., 2016; Patton, 2002). To find sufficient patterns, rather than be exhaustive of the literature, we conducted a comprehensive search of 6 mos of article publications (criterion sampling then random sampling, Suri, 2011). For the purposes of this phase, we were interested in articles that included references to professionals working with children ages 3-5 in the US. We conducted a search of research and practitioner journals to understand terms used for professionals and settings (described here and in more detail in the Appendix). To identify research journals, we reviewed journals listed in the Web of Science social science database under "Education and Education Research" ( $n=231$; Web of Science, 2016) and then visited each journal's home page to identify those indicating inclusion of articles/research related to EC. To identify practitioner journals, which may not have been readily available from the Web of Science list we used a multi-pronged sampling procedure (Maxwell, 2013) to identify potential articles for inclusion. First, the first and third authors compiled a list of 10 common EC practitioner journals. Next, they identified 10 researchers well-known for publishing in practitioner journals and reviewed the Curricula Vita of these researchers for additional titles of practitioner journals to be added to 
the list $(n=10)$. In addition, publication outlets of co-authors of the practitioner pieces were added to the list $(n=5)$.

Once a research or practitioner journal was identified as possibly including publications regarding EC professionals, a research assistant reviewed the abstracts for each article in 6 mos of published issues to identify articles about or for EC professionals that were also situated in or described EC settings. Thus, all included articles had to provide terms for EC professionals and settings. Articles that were relevant were identified for possible coding. In order to generate a representative sampling of terms used to refer to EC professionals and settings, we randomly selected one article per issue to code (although some journals had multiple issues within a 6 mo period; Suri, 2011). Search and coding protocols are provided in the Appendix. In total, 52 articles -26 research articles and 26 practitioner articles - representing 22 journals were included. See the Appendix for a list of journals with included articles.

Phase 2. The first author collected Phase 2 data via interviews with 20 EC professionals. A semi-structured interview protocol was designed to gather background information and elicit professionals' perspectives on their roles and settings. We asked three different questions focused on professionals' perspectives of their roles: What do you call your early childhood program?, What label would you use to describe where you come to work?, and Do you see a difference in the types of words used to describe early childhood programs and people that work in early childhood programs? If so, what is the difference?

Phase 3. We collected Phase 3 data through online surveys designed to gain a new sample of 112 educators' perspectives on their roles and settings. Data collection was informed by Phase 2 data collection which aligns with sequential design practices (Creswell \& PlanoClark, 2011). Participants were asked three questions at the beginning of the survey similar to the 
questions asked in the interviews (Phase 2), including two fixed-choice questions and one openresponse question. In the two fixed-choice questions, participants were asked to select which term best described their role and setting. The response options for these questions came from the most frequent terms for role and setting identified in the Phase 2 data. Participants were also asked an open-comment question similar to the third question asked in the interview, Do you see a difference in the words used to describe early childhood programs (ex. preschool, daycare, childcare center) and people (ex. educator, caregiver, teacher) that work in early childhood programs? If so, what is the difference? Importantly, prior to administration, this question was vetted via cognitive interviews (Desimone \& Flock, 2004) with five participants to ensure clarity.

\section{Data Analyses}

Data from all three phases were used to understand how multiple informants describe the roles and places for working with young children. Thus, following mixed methods procedures, we sought to integrate findings across the data sources, both in informing the analytic process from Phase 2 to Phase 3 and then more broadly to compare the preference for terms by data source (Sandelowski, 2000; Tashakkori \& Teddlie, 2003).

Phase 1. We conducted a content analysis (Hsieh \& Shannon, 2005) of the included articles to identify each unique term used to refer to EC professionals and settings. This provided an understanding of the range of terms utilized in the literature. A research assistant coded the entire dataset and following recommendations based on the sample size (O'Conner \& Joffe, 2020), $10 \%$ of articles were double coded by the first author; interrater agreement was $90 \%$ for participant terms and $89 \%$ for setting terms. All unique terms within an article were identified; thus, articles could include more than one term. Findings were enumerated (Dey, 2003) to 
quantify the frequency of terminology usage across journals (Tables 1 and 2).

Phase 2. We used an inductive approach (Maxwell, 2013) to examine the Phase 2 interview data for emerging themes in participants' views regarding terms for professionals and EC settings. First, we examined responses to each of the three questions individually and then looked across responses to all three questions to identify cross-cutting themes (Marshall \& Rossman, 2006). We utilized this analytic strategy because the patterns in responses regarding participants' roles and work settings involved the same themes. The resulting framework described their combined responses to the three questions. The themes are listed and defined in Table 4. There was one axial theme around which all the other themes revolved (Corbin \& Strauss, 2008).

Phase 3. Phase 3 data were intended to confirm, disconfirm, and elaborate the findings in Phase 2 with a larger sample (Maxwell, 2013). Fixed-choice responses were analyzed descriptively. The open-responses were coded with a priori and emergent coding methods (Corbin \& Strauss, 2008) to replicate and extend findings from the Phase 2 interview data. Specifically, we began using the codes generated in Phase 2 while allowing for new codes/themes to emerge as appropriate. Four new themes were present in the Phase 3 data (Table 4). Importantly, three of the new themes connected to the axial theme identified in Phase 2; whereas the "no difference" theme did not.

\section{Results}

We present our findings regarding most frequent terms using the quantitative data across phases to compare responses. We then present the qualitative findings from Phases 2 and 3 which provide insight into the patterns in the quantitative data. Our results indicate that, although the names used to refer to the EC workforce may seem a superficial issue, for these participants 
the roles they assumed, the way they carried out their work, and how they positioned themselves in the complex field of EC were encapsulated in choices of labels, and what those choices indicated about the nature and value of the work.

\section{Most Frequent Terms}

As displayed in Table 2, the most preferred term for role across all data sources was "teacher." This term was used in 74 articles ( $n=18$ research articles, $n=56$ practitioner articles) and selected by $73.5 \%$ of participants across Phases 2 and $3(n=13$ Phase $2, n=84$ Phase 3$)$. "Educator" was the second most common term but appeared less frequently. This term was used in 26 articles and selected by $15.2 \%$ of participants across Phases 2 and $3(n=1$ Phase 2, $n=19$, Phase 3). Importantly, there was a range of terms used in articles and provided by participants, particularly from the participants in Phase 2. However, most of these were infrequent, appearing only once or twice.

There was also agreement among all data sources regarding the preferred term for setting. The professionals in Phases 2 and 3 most frequently used the term "preschool" for setting. This term was selected by $40.9 \%$ of participants ( $n=8$ Phase $2, n=46$ Phase 3 ) with "early childhood program" used the next most commonly by $25.8 \%$ of participants $(n=1$ Phase $2, n=33$ Phase 3). This pattern was similar to that of journals with the most frequent term across articles being "preschool" ( $n=12)$ followed by Head Start $(n=11)$ a specific setting for 3-5 year olds. There were some notable differences between practitioner and researcher articles with researcher articles tending to favor classroom and school related terms (see Table 3).

\section{Participants' Explanations for Preferred Terms}

Within the Phase 2 interview data, there was one axial theme to which all the other themes connected (Table 4). This axial theme was the idea that participants' work was teaching 
or educating young children within preschool settings to prepare them for formal schooling. This notion was strongly tied to participants' views of themselves as teachers and was exemplified in participants' responses such as,

I think we're more than a daycare. Like, we actually — we're teaching; we're helping develop these young children into being able to be productive members of society and, you know, really giving them the tools they need to succeed in school.

Here the participant clearly links their work as a teacher to preparing children for school as well as general life success. These ideas about participants' work sometimes evoked emotional responses such as in the following quote,

...this is a school...the lengths that we go to, to make sure that our kids are safe and learn the things that they need to know, this is school. Like I'm a teacher, and I hate when people call me, a daycare provider or a caregiver or anything like that. Like I'm - this is-we're teachers here. Like we do a lot.

The participant described both their strong feelings about how people refer to their role and work while embodying the idea that their work was teaching and supporting children's learning.

As part of this view of themselves as teachers, some participants directly contrasted their role and setting with daycare and babysitting. This was evident in the prior quote as well as in others' responses wherein daycare and babysitting were viewed as not having teaching or educational purposes. For example, one participant said,

I just don't like the term "daycare" because I'm just not here just sitting around with them. And we do play, but there's learning involved in that, and I can back up what I do, without looking at a book. Or I can back up what I do, why it's developmentally good, what I teach... I don't think that's daycare. I think daycare is like babysitting at home, something that a 13-year-old does.

The participant introduced the idea that their work was not a daycare because they understood how play facilitated learning and had the expertise to link that to children's development specialized knowledge. Another participant elaborated on the difference between a teacher and a daycare worker, saying, "There's a difference between a teacher and a caretaker or a daycare 
worker. Teachers I feel like are more structured.... they have to have certain guidelines to follow... where caretakers or daycare workers, it's a babysitting job and they can just sit back and they can watch them play." In this response the teacher refers to the guidelines and structure that make her work teaching not babysitting.

For most participants in the sample, there existed a clear difference between the work of providing care and the work of educating young children. These teachers accorded an elevated status to the work of teaching over caregiving with clear divisions between programs that were educational and programs that were more care-based as reflected in the contrast between "day care" and "preschool" and "caregiver" versus "teacher." In the evolving field of EC education, with longstanding and changing commitments to caregiving and educating, the participants in this study generally chose to forefront the education part of their work, possibly given the perceived lower status of caregiving. In one counter example, a participant commented: “As a teacher I believe that I have work combining different roles and responsibilities. I'm an educator and a caregiver at the same time, I use curriculum and research with a social emotional approach." These caregiving roles were a minority in teachers' responses but were evidenced in some participants' responses (e.g., mother, adult male figure, doctor; Table 2).

In addition to the emphasis on supporting children's learning rather than merely caregiving, other themes further elaborated the work of teaching as the central role of EC workers. These themes included that teachers in preschools: 1) used a curriculum, 2) planned for instruction, 3) held specialized expertise, and 4) worked with children during an important developmental period (Table 4). Some participants discussed the idea that there was a curriculum or a structured set of activities that were used during their teaching as in the example presented previously. Another participant said, "It's more structured activities with the students. So-and 
they're all broken down by different sections like cognitive, and writing, science and math, and the other centers [programs] aren't," expressing how they structured activities for children in different domains to facilitate their academic learning.

Additionally, participants also emphasized the importance of the intentional planning involved in their work. Discussing lesson plans, one participant stated, "I don't think a lot of people understand that preschool is like a school and they think it's, yeah, little kids, so its daycare and they just play all day. I think they don't realize it has lesson plans and all that stuff." The participant identified the planning that goes into the work of teaching, which made their setting more like "school."

Relatedly, EC professionals wanted recognition for the specialized expertise needed for the work that they were doing. This was exemplified in the next quote wherein the participant expressed how the expertise they had (degree, experience, background, and knowledge) played a critical role in preparing young children to succeed in kindergarten and beyond. In reflecting on the difference in terms they said, “...that experience, that background, and the knowledge of what you know the children need to know if they go to kindergarten," was what differentiated terms.

Finally, participants also viewed EC as an important period in children's development and, as such, identified that the work they were doing was critical. Describing the value of EC education, one participant stated, "We know that the research shows that EC education is so important, and the first five years of life are so vital for success later on. In terms of social and emotional development, academic success, things like that." Here the participant explicitly linked research evidence to the reasons why EC played an essential role in children's learning and its influence on multiple aspects of children's development and academic growth. 
Confirming and elaborating data with Phase 3 participants. This pattern of viewing EC as teaching in preschool settings and as preparation for formal schooling was confirmed in the Phase 3 open-response data with about half of the participants $(49 \% ; n=55)$ reporting that their work was to teach young children in preparation for formal schooling. One exemplar of this is the following response,

Daycare in my opinion is mainly for children who are in care of a babysitter. A preschool is mainly to prepare children for kindergarten. Children in a daycare might not have [a] structured school readiness program. Preschool where I work definitely prepare[s] children for success.

The idea that participants were not babysitters/daycare was also present in several participant responses $(14 \%, n=16)$. Furthermore, expertise was a linking theme for some participants $(13 \%$; $n=14$ ), such as in the following exemplar in which a teacher contrasted their work with daycare saying the, “...programs are more structured, consistent, [with] qualified/educated teachers and assistants." Phase 3 participants also identified using a curriculum $(15 \% ; n=17)$ and planning $(2 \% ; n=2)$ as supporting children's preparation for formal schooling and identified EC as an important developmental period $(3 \% ; n=3)$.

Four new themes emerged in the Phase 3 data, three of which were connected to the axial theme. These were ideas around professionalism, quality, and funding (Table 4). Some participants $(11 \% ; n=12)$ described professionalism as an aspect that was important in differentiating between roles and settings. For example, on participant wrote, "Early childhood programs and preschools convey the education and professionalism of this area of focus, as do the terms educator and teacher." A small set of participants $(4 \% ; n=6)$ also reported that quality was a reason for differences among settings. As one participant wrote, "people associate early childhood programs with an accredited center or a Head Start program.” Also infrequent were participants' comments that differences in terms could be attributed to EC program funding 
mechanisms $(5 \% ; n=6)$, such as in the comment, "... some cost money and have an abundance of resources, some are public and often have resources, and some are there to just watch the children for daycare purposes."

New patterns in the Phase 3 data. One new disconnected theme emerged in the Phase 3 responses. Whereas all participants in Phase 2 indicated that they felt there were differences between the terms used to describe EC professionals and their settings, $25 \%$ of Phase 3 participants $(n=28)$ reported that they did not see a difference in the terms. This was evident in responses such as "No" or "I do not see a difference." One participant further elaborated on their response writing, "No I don't see a difference. No matter what word is described [sic] the program or the people that work in the field, we all serve a purpose in helping children grow learn and develop." In another representative comment, a participant stated, "I don't really see a difference. The terms seem to be interchangeable." Importantly, even within these later two quotes are ideas about the importance of EC as supporting the learning of young children. This pattern was common in these types of responses. Thus, even though for many of the participants labels did not seem to matter, they still held important views regarding their work in supporting children's learning.

\section{Discussion}

The purpose of this study was to understand the labels used to describe EC professionals and settings in researcher and practitioner journals as well as by professionals themselves. Although how journals label professionals and how professionals label themselves and their work may seem a mundane research question, our findings reflect the field's and professionals' own sense of themselves as knowledgeable, professional, and legitimate even as they serve in professional positions that are sometimes delegitimized through rhetoric, low pay, and the 
persistence of everyday assumptions about the educational importance of the early years

(Whitebook et al., 2014). This work provides important insights for communicating across the field and supporting the ongoing professionalization of the EC workforce. An advantage of this study was the larger sample size than previous studies of this topic which allowed us to confirm and extend qualitative findings to a broader sample in the US context.

\section{Alignment across Data Sources}

We found alignment across informants - research journals, practitioner journals, and professionals - regarding the way that EC professionals and settings were described. The preferred term was "teacher" demonstrating a general understanding across the field that those working with young children are supporting learning, with teachers highlighting their role in the educational process. This was further reflected in the overall sentiment of participants that they were preparing children for formal schooling and/or developing children's readiness skills, and that where they worked was a preschool. Even many of the participants in Phase 3 who reported that they saw no differences across terms still reported that a key role was to support children's development and learning, regardless of label.

However, not all professionals were focused on their role of preparing children for formal schooling, reflecting variation within the field. We observed that participants, particularly in Phase 2, included other terms such as "provider," "mother," "social coach," and “doctor," indicating that they also recognized the caregiving aspect of their work. However, few participants described their role solely as nurturing or caregiving and none of these terms were present in the journal articles. This is similar to what has been noted by other researchers, particularly with the increased focus on more academic skills with teachers reporting a dual role of education and care or even shifting more towards education (Harwood et al., 2013; Löfgren, 
2016; Rentzou, 2019; Scherr \& Johnson, 2019; Sims, 2014).

Although preschool was the most commonly used term across phases, we observed variability in preferences for the terms for EC settings. Importantly, however, the terms did tend to cluster around words used to describe formal K-12 settings including words like "school" or “classroom." A preference for the word "preschool" by the professionals themselves is fitting with these terms, showing alignment with the traditional K-12 system and is consistent with professionals' description of their work as preparing children for formal schooling. This variability may also be tied to the difference in funding mechanisms (IOM \& NRC, 2012; Whitebook et al., 2018) and specific setting types, such as Head Start which was the second most frequently used term by journals.

\section{US Context and Perceptions of EC Professionals}

In both the interviews and open-response items, participants drew a strong contrast between their work and babysitting - seeking to legitimize their work as critical for supporting children's early learning. Furthermore, many of these participants often referenced public views of their work when making this contrast, seemingly wanting people to understand the expertise and planning that went into being an EC professional and the educational role of their settings. The finding that many participants referenced public perceptions suggests that they encountered negative or dismissive views of their work on a fairly regular basis mirroring that of other emerging research (Scherr \& Johnson, 2019; Sisson \& Kroeger, 2017). Thus, as others have argued before, more work is needed to elevate public views of the work of EC education in the US (Whitebook et al., 2014).

Additionally, teachers' views may be tied to efforts to legitimize or "professionalize" the EC workforce. Indeed, focusing the teaching and learning aspects of the work not only 
underscores the specialized training in which many EC teachers participate but also aligns EC more closely with K-12 systems and teachers. The clear shift away from the term "caregiver" signals that professionals want recognition for their role in education beyond that of caregiving. This finding aligns with recent literature from other countries (Einarsdóttir, 2003; Harwood et al., 2013; Shpancer et al., 2008; Sim, 2014) where caregiving has played a diminished role in EC education. However, although there is merit in these perspectives a critical part of EC education is attending to children's social-emotional development and providing nurturing supportive environments (Hamre et al., 2014; Markowitz et al., 2017). It may be that when framing teaching and professionalism the critical role of care should be acknowledged and receive appropriate recognition for its role in child development.

EC setting quality, an ongoing issue in the US context (Quality Compendium, 2019), was also something that explained professionals' preferred terms. Although efforts are being made at the state-level across the country to improve setting quality, there is still a range in the quality of EC programming in the US both within and across settings. Thus, participants were observing this difference in their understanding of what terms described. One indicator of quality in EC setting is the use of curricula and assessments (Markowitz et al., 2018; Weiland et al., 2018). It should be noted that participants in this study were all working in settings that utilized language and literacy assessments and curricula and only included teachers from two regions within the US. Thus, there may be a bias in the participant sample in favor of terms associated with teaching and academic preparation. Future studies should expand the samples of professionals and settings to gain a better understanding of a range of practitioner views.

\section{Conclusion}

The perspective of teachers in interviews and survey responses show that labels matter to 
the professionals working in EC. EC professionals find themselves working in a patchwork, mixed market, rapidly changing field that in recent years has become increasingly aligned with educational approaches common in K-12 schooling in the U.S. Yet, as Nesbit and Farran (2021) note, "The United States has not reconciled the two major functions of care and education in early childhood" (p. 13). Left to straddle the line between education and care, teachers, draw a distinction between providers of care and those who fill a role much more consonant with public school teaching, including the use of structure, curriculum, and assessment. In navigating the divide, the teachers' words show how a kind of legitimacy rests in being seen as teachers, while the part of the work of EC associated with nurturance, care, and at times play is downplayed in efforts to elevate the status of the field. It may be in the push to professionalize EC, we have inadvertently reinforced the schism between care and education, rather than creating curricular tools, assessments, and professional preparation that supports teachers in understanding care and education as equally instrumental to children's positive development, especially their learning. 


\section{References}

Barnett W. S., Friedman-Krauss, A., Gomez, R., Horowitz, M., Weisenfeld, G. G., Brown, K. C., \& Squires, J. H. (2016). The state of preschool 2015: State preschool yearbook. National Institute for Early Education Research. http://nieer.org/wpcontent/uploads/2016/05/Yearbook_2015_rev1.pdf

Bassok, D., Latham, S., \& Rorem, A. (2016). Is kindergarten the new first grade? AERA Open. https://doi.org/10.1177/2332858415616358

Benoot, C., Hannes, K. \& Bilsen, J. (2016). The use of purposeful sampling in a qualitative evidence synthesis: A worked example on sexual adjustment to a cancer trajectory. $B M C$ Medical Research Methodology, 16(21). https://doi.org/10.1186/s12874-016-0114-6

Boyd, M. (2013). "I love my work but...” The professionalization of early childhood education.” The Qualitative Report, 18(71), 1-20. https://doi.org/10.46743/2160$\underline{3715 / 2013.1470}$

Child Care Aware. (2019). Child care providers. https://usa.childcareaware.org/about/child-careproviders/

California Department of Education. (2011). California early childhood educator competencies. https://www.cde.ca.gov/sp/cd/re/documents/ececompetencies2011.pdf

Corbin, J., \& Strauss, A. (2008). Basics of qualitative research: Techniques and procedures for developing grounded theory. Sage.

Cox, M. E., Hollingsworth, H., \& Buysse, V. (2015). Exploring the professional development landscape: Summary from four states. Early Childhood Research Quarterly, 32, 116126. https://doi.org/10.1016/j.ecresq.2015.03.002

Creswell, J. W., \& Plano Clark, V. L. (2011). Designing and conducting mixed methods 
research. Thousand Oaks, CA: Sage Publications.

Desimone, L. M., \& Le Floch, K. C. (2004). Are we asking the right questions? Using cognitive interviews to improve surveys in education research. Educational Evaluation and PolicyAnalysis, 26(1), 1-22. https://doi.org/10.3102/01623737026001001

Dey, I. (2003). Qualitative data analysis: A user friendly guide for social scientists. New York, NY: Routledge.

Einarsdóttir, J.H. (2003). The role of preschools and preschool teachers: Icelandic preschool educators' discourses. Early Years: An International Journal of Research and Development, 23(2), 103-116. https://doi.org/10.1080/09575140303110

For Our Babies (2019). Our Mission. WestEd.

Hamre, B., Hatfield, B., Pianta, R., \& Jamil, F. (2014). Evidence for general and domain-specific elements of teacher-child interactions: Associations with preschool children's development. Child Development, 85(3), 1257-1274. https://doi.org/10.1111/cdev.12184

Harwood, D., Klopper, A., Osanyin, A., \& Vanderlee, M. L. (2013). 'It's more than care': Early childhood educators' concepts of professionalism. Early Years, 33(1), 4-17. https://doi.org/10.1080/09575146.2012.667394

Head Start Early Childhood Learning \& Knowledge Center. (2019). Staff qualifications. https://eclkc.ohs.acf.hhs.gov/policy/45-cfr-chap-xiii/1302-91-staff-qualifications$\underline{\text { competency-requirements }}$

Hsieh, H. F., \& Shannon, S. E. (2005). Three approaches to qualitative content analysis. Qualitative Health Research, 15(9), 1277-1288. https://doi.org/10.1177/1049732305276687

Institute of Medicine \& National Research Council. (2012). The early childhood care and 
education workforce: Challenges and opportunities: A workshop report. National Academies Press.

Jessen-Howard, S., Malik, R., Workman, S., \& Hamm, K. (2018). Understanding infant and toddler child care deserts. Center for American Progress. https://www.americanprogress.org/issues/earlychildhood/reports/2018/10/31/460128/understanding-infant-toddler-child-care-deserts/

Jónsdóttir, A. H., \& Coleman, M. (2014). Professional role and identity of Icelandic preschool teachers: Effects of stakeholders' views. Early Years, 34(3), 210-225. https://doi.org/10.1080/09575146.2014.919574

Kansas Department of Health and Environment. (2019). Kansas laws and regulations for licensing preschools and childcare centers. http://www.kdheks.gov/bcclr/regs/ccc/Preschools_and_Child_Care_Centers_all_sections. pdf

Löfgren, H. (2016). A noisy silence about care: Swedish preschool teachers' talk about documentation. Early Years, 36(1), 4-16. https://doi.org/10.1080/09575146.2015.1062744

MacFarlane, K., \& Lewis, T. (2004). Childcare-human services or education: A genealogical approach. Contemporary Issues in Early Childhood, 5(1), 51-67. https://doi.org/10.2304/ciec.2004.5.1.9

Madill, R., Blasberg, A., Halle, T., Zaslow, M., \& Epstein, D. (2016). Describing the preparation and ongoing professional development of the infant/toddler workforce: An analysis of the National Survey for Early Care and Education data (OPRE Report \#201616). Office of Planning, Research and Evaluation, Administration for Children and 
Families, U.S. Department of Health and Human Services.

Markowitz, A. J., Bassok, D. \& Hamre, B. (2018). Leveraging development insights to improve early childhood education. Child Development Perspectives, 12(2), 87-92. https://doi.org/10.1111/cdep.12266

Marshall, C. \& Rossman, G. B. (2006). Designing qualitative research. Sage.

Maryland Department of Education. (2019). Child care providers. https://earlychildhood.marylandpublicschools.org/child-care-providers

Maxwell, J.A. (2013). Qualitative research design: An interactive approach. Sage.

Montana Department of Health and Human Services. (2019). STARS center standards. https://dphhs.mt.gov/Portals/85/hcsd/documents/ChildCare/STARS/CenterStandards.pdf

National Association for the Education of Young Children. (2009). Developmentally appropriate practice in early childhood programs serving children birth through age 8. https://www.naeyc.org/sites/default/files/globallyshared/downloads/PDFs/resources/position-statements/PSDAP.pdf

Nebraska Department of Education. (2013). Nebraska's core competencies for early childhood professionals: Knowledge and skills needed to effectively work with children ages birth to five years. https://www.education.ne.gov/wpcontent/uploads/2017/07/professional_corecomp.pdf

Nebraska Department of Health and Human Services. (2021). Child Care Licensing. https://dhhs.ne.gov/licensure/Pages/Child-Care-Licensing.aspx

New York State Early Childhood Advisory Council. (2019). New York State Early Learning Guidelines: A child development resource for educators of children birth through eight. https://earlychildhoodny.org/elg/viewer/Early_Learning_Guidlines-Revised-2020- 
webversion.html\#page $=1$

Nesbitt, K. T., \& Farran, D. C. (2021). Effects of prekindergarten curricula: Tools of the Mind as a case study. Monographs of the Society for Research in Child Development, 86(1), 7119. https://doi.org/10.1111/mono.12425

O’Connor, C, \& Joffe, H. (2020). Intercoder reliability in qualitative research: Debates and practical guidelines. International Journal of Qualitative Methods. https://doi.org/10.1177/1609406919899220

OECD. (2017). Starting strong V: Transitions from early childhood education and care to primary education. OECD Publishing. https://doi.org/10.1787/9789264276253-en

Ohio Department of Education. (2015). Ohio's early childhood core knowledge \& competencies. http://education.ohio.gov/getattachment/Topics/Early-Learning/ProfessionalDevelopment-for-Early-Childhood-Teach/Ohio-Early-Learning-Core-Knowledge-andCompetencie/CoreKnowledge.pdf.aspx

Quality Compendium. (2019). A catalog and comparison of quality initiatives like Quality Rating and Improvement Systems (QRIS). https://qualitycompendium.org/

Patton, M. Q. (2002). Qualitative Evaluation and Research Methods. Sage Publishing. Rentzou, K. (2019). Greek early childhood educators' conceptualization of education, care and educare concepts. Early Years, 39(2), 148-162. https://doi.org/10.1080/09575146.2017.1361386

Sandelowski, M. (2000). Combining qualitative and quantitative sampling, data collection, and analyses techniques in mixed-methods research. Research in Nursing \& Health, 23(3), 246-255. https://doi.org/10.1002/1098-240X(200006)23:3<246::AID-NUR9>3.0.CO;2- 
Scherr, M., \& Johnson, T.G. (2019). The construction of preschool teacher identity in the public school context. Early Child Development and Care, 189(3), 405-415. https://doi.org/10.1080/03004430.2017.1324435

Shpancer, N., Dunlap, B., Melick, K.M., Coxe, K., Kuntzman, D., Sayre, P.S., Toto, C., \& Spivey, A.T. (2008). Educators or babysitters? Daycare caregivers reflect on their profession. Child Care in Practice, 14(4), 401-412. https://doi.org/10.1080/13575270802267994

Sims, M. (2014). Is the care-education dichotomy behind us?: Should it be?. Australasian Journal of Early Childhood, 39(4), 4-11. https://doi.org/10.1177/183693911403900402

Sisson, J. H. (2016). The significance of critical incidents and voice to identity and agency. Teachers and Teaching: Theory and Practice, 22(6), 670-682. https://doi.org/10.1080/13540602.2016.1158956

Sisson, J. H., \& Kroeger, J. (2017). 'They get enough of play at home’: A Bakhtinian interpretation of the dialogic space of public school preschool. Early Child Development and Care, 187(5-6), 812-826. https://doi.org/10.1080/03004430.2016.1252533

Suri, H., (2011). Purposeful sampling in qualitative research synthesis. Qualitative Research Journal, 11(63). https://doi.org/10.3316/QRJ1102063

Tashakkori A, \& Teddlie, C. (2003). Handbook of mixed methods in social and behavioral research. Sage.

Web of Science. (2016). Social sciences citation index-education \& educational researchjournalist. Clarivate. http://mjl.clarivate.com/cgi-bin/jrnlst/jlresults.cgi

Weiland, C., McCormick, M., Mattera, S., Maier, M., \& Morris, P. (2018). Preschool curricula and professional development features for getting to high-quality implementation at 
scale: A comparative review across five trials. AERA Open, 4(1). https://doi.org/10.1177/2332858418757735

Whitebook, M., Gomby, D., Bellm, D., Sakai, L., \& Kipnis, F. (2009). Preparing teachers of young children: The current state of knowledge, and a blueprint for the future. Part 2: Effective teacher preparation in early care and education: Toward a comprehensive research agenda. Policy Report. Center for the Study of Child Care Employment, University of California at Berkeley. https://cscce.berkeley.edu/files/2009/teacher_prep_2.pdf

Whitebook, M., McLean, C., Austin, L.J., \& Edwards, B. (2018). Early childhood workforce index 2018. Center for the Study of Child Care Employment, University of California at Berkeley. https://cscce.berkeley.edu/early-childhood-workforce-2018-index/

Whitebook, M., Phillips, D., \& Howes, C. (2014). Worthy work, STILL unlivable wages: The early childhood workforce 25 years after the national child care staffing study. Center for the Study of Child Care Employment, University of California, Berkeley. https://cscce.berkeley.edu/files/2014/ReportFINAL.pdf

Workgroup on the Early Childhood Workforce and Professional Development, Brandon, R., Burchinal, M., Kipnis, F., Weber, R., Whitebook, M., \& Zaslow, M. (2016). Proposed revisions to the definitions for the early childhood workforce in the standard occupational classification. Office of Planning, Research and Evaluation, Administration for Children and Families, U.S. Department of Health and Human Services. https://www.acf.hhs.gov/sites/default/files/opre/soc_white_paper_june_2014_518_508.pd 


\section{Appendix - Phase 1 Journal Search Protocol and Included Journals}

1. Selecting journals

a. Research journals: Review journals listed in the Web of Science, social science database under "Education and Education Research" (http://science.thomsonreuters.com/cgi-bin/jrnlst/jlresults.cgi?PC=SS\&SC=HA) $n=$ 231

b. Practitioner journals: We will use a two-pronged snowball sampling procedure to identify possible journals for inclusion. Beginning with a list of 10 journals and 10 researchers generated by the authors. The CVs of the researchers will be examined for the titles of practitioner journals and added to our initial list (keep track of the number of new journals added). In addition, co-authors of practitioner pieces will be added to the list to check their CVs for publications (keep track of the number of researchers added to the list). Once those have been thoroughly vetted, we will cross reference the reference list with our list of practitioner journals and add any new journals to the list (keep track of the number of added journals).

c. For each journal (RESEARCH or PRACTITIONER) visit the home page and print "aims/purpose/scope/about journal." Review descriptions for indications that the journal includes articles/research related to early childhood (could be of any topic about early childhood).

i. Key terms could include: references to children three to five, daycare, early learning, early childhood, preschool, prekindergarten, kindergarten, early education, young children, but are not limited to these terms.

d. Based on this inspection:

i. Any possible indication that journal includes articles about early childhood should be highlighted.

ii. If there is no indication one way or the other, highlight it as unclear.

iii. If it is clearly not inclusive of early childhood education then write "exclude" on top of the summary.

e. A second coder will examine the abstract for decision about inclusion.

2. Inclusion coding

a. Look at four most recent issues of journal (write the Volume \& Issue numbers)

i. Examine if there are any relevant articles by reviewing the abstracts

ii. Examine for references to professionals teaching 3-5 year olds

iii. Examine to make sure research is with US populations

iv. Print relevant abstracts

v. Select articles for coding - at most 4 articles (1/issue)

1) If more than one eligible article per issue randomly select an article to code.

3. For terminology coding (coding for language they use about participants)

a. Review:

i. Purpose (RESEARCH and PRACTITIONER)

ii. Research Questions (most likely RESEARCH only) 
iii. Methods through the description of the setting and the participants including any tables/table headings/table notes with descriptive information (most likely RESEARCH only)

iv. Introduction - where they outline basic overview (PRACTITONER only)

v. Conclusion - where articles are summarized (PRACTITONER only)

b. Code for the study setting (all language related to where children learn)

i. Do not code the word "classroom" on its own, only code if there is a modifier for classroom (e.g., "prekindergarten classroom")

ii. Do not need to code for modifiers related to SES, public/private, half-day/fullday, geographic location (e.g., rural, urban, etc.)

c. Code for the participants (all language related to who is teaching the children)

Table of Journals

\begin{tabular}{lcc}
\hline \multicolumn{1}{c}{ Journal Name } & Number of Articles* & Classification \\
\hline American Educator & 3 & Practitioner \\
Anthropology \& Education Quarterly & 1 & Researcher \\
Asia-Pacific Journal of Teacher Education & 1 & Researcher \\
The California Reader & 1 & Practitioner \\
Childhood Education & 2 & Researcher \\
Computers and Education & 1 & Researcher \\
Current Issues in Education & 1 & Practitioner \\
Dimensions of Early Childhood & 2 & Practitioner \\
Early Childhood Development and Care & 4 & Researcher \\
Early Childhood Education Journal & 4 & Researcher \\
Early Childhood Research and Practice & 4 & Researcher \\
Early Childhood Research Quarterly & 1 & Researcher \\
Early Education and Development & 2 & Researcher \\
Education Week & 2 & Practitioner \\
The Elementary School Journal & 1 & Researcher \\
Infants \& Young Children & 2 & Researcher \\
Literacy Research and Instruction & 2 & Researcher \\
NHSA Dialog & 4 & Practitioner \\
The Reading Teacher & 2 & Practitioner \\
Studies in Educational Evaluation & 1 & Researcher \\
Teaching Young Children & 3 & Practitioner \\
Young Children & 4 & Practitioner \\
Young Exceptional Children & 4 & Practitioner \\
\hline
\end{tabular}

*Up to one article per issue within a 6 mos timeframe could be sampled. This number may fluctuate across journals based on both the number of issues and eligible articles. 
Table 1

Demographic Characteristics of Participants - Phases $2(n=20)$ and Phase $3(n=112)$

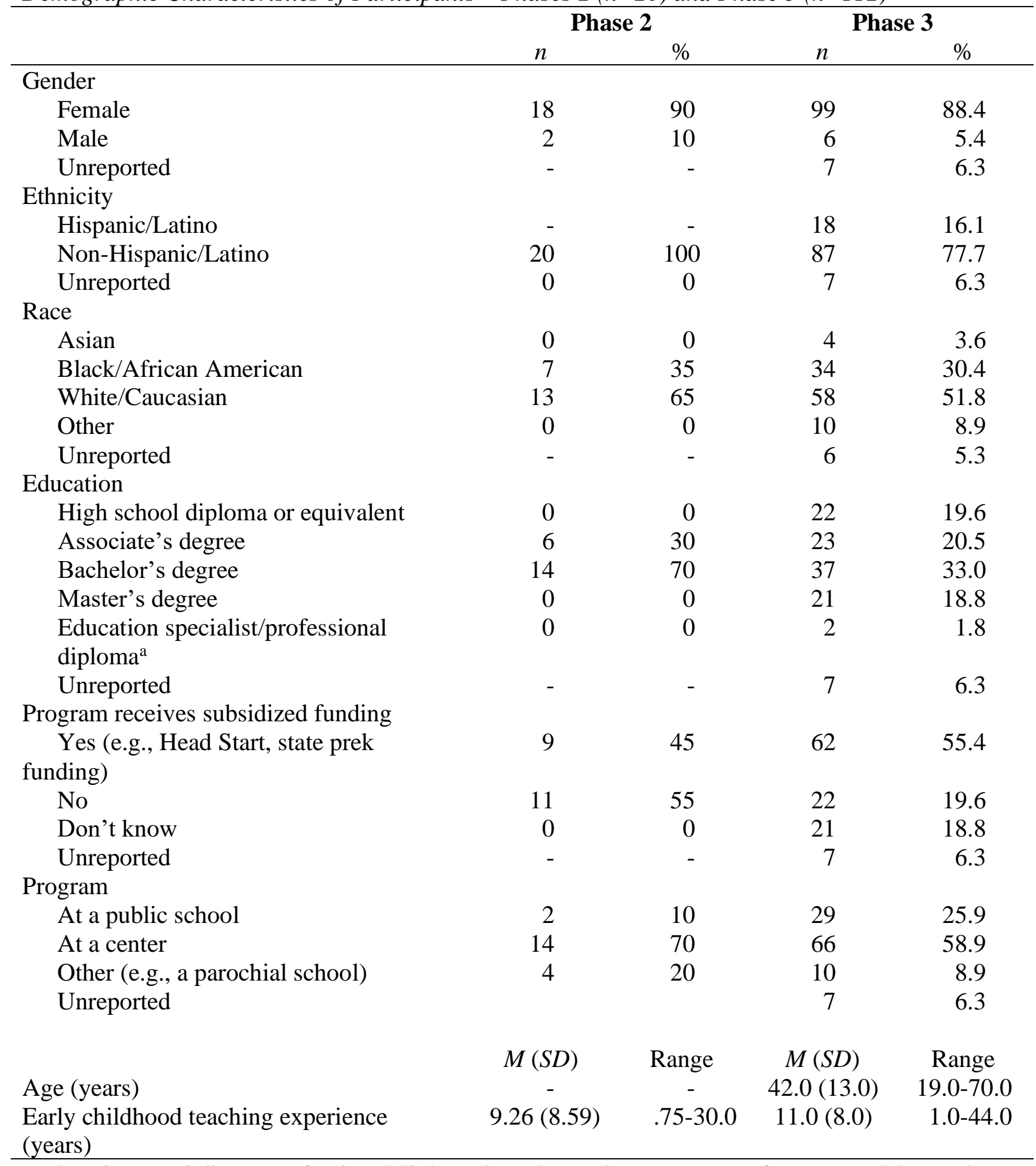

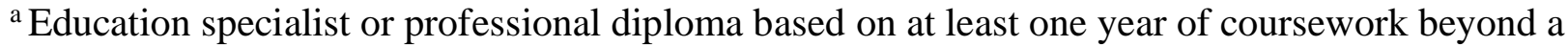
Master's degree. 
Table 2

Frequency of Terms for Role

\begin{tabular}{lcccccc}
\hline & $\begin{array}{c}\text { Total } \\
\text { Across } \\
\text { Article }\end{array}$ & $\begin{array}{c}\text { Research Practitioner } \\
\text { Articles } \\
(\boldsymbol{n = 2 6})\end{array}$ & $\begin{array}{c}\text { Articles } \\
(\boldsymbol{n}=\mathbf{2 6})\end{array}$ & $\begin{array}{c}\text { Total } \\
\text { Participant } \\
\text { Responses }\end{array}$ & $\begin{array}{c}\text { Phase 2 } \\
\text { responses } \\
(\boldsymbol{n}=\mathbf{2 0})\end{array}$ & $\begin{array}{c}\text { Phase 3 } \\
\text { responses } \\
(\boldsymbol{n}=\mathbf{1 1 2})\end{array}$ \\
\hline Teacher & 43 & 23 & 20 & 97 & 13 & 84 \\
Educator & 18 & 8 & 10 & 20 & 1 & 19 \\
Preschool Teacher & 8 & 8 & 0 & 0 & 0 & 0 \\
EC Teacher & 8 & 5 & 3 & 0 & 0 & 0 \\
Practitioner & 6 & 4 & 2 & 0 & 0 & 0 \\
EC Educator & 6 & 3 & 3 & 0 & 0 & 0 \\
Professional & 3 & 1 & 2 & 4 & 0 & 4 \\
EC Professional & 3 & 1 & 2 & 0 & 0 & 0 \\
Provider & 0 & 0 & 0 & 5 & 1 & 4 \\
Facilitator & 0 & 0 & 0 & 5 & 5 & 0 \\
Co-teacher & 0 & 0 & 0 & 3 & 3 & 0 \\
Mother & 0 & 0 & 0 & 3 & 3 & 0 \\
Preschool teacher & 0 & 0 & 0 & 2 & 2 & 0 \\
Lead teacher & 0 & 0 & 0 & 1 & 1 & 0 \\
Mentor & 0 & 0 & 0 & 1 & 1 & 0 \\
Prompter & 0 & 0 & 0 & 1 & 1 & 0 \\
Mediator & 0 & 0 & 0 & 1 & 1 & 0 \\
Social coach & 0 & 0 & 0 & 1 & 1 & 0 \\
Manners trainer & 0 & 0 & 0 & 1 & 1 & 0 \\
Role model & 0 & 0 & 0 & 1 & 1 & 0 \\
Adult male figure & 0 & 0 & 0 & 1 & 1 & 0 \\
Doctor & 0 & 0 & 0 & 1 & 1 & 0 \\
Chief & 0 & 0 & 0 & 1 & 1 & 0 \\
Staff & 0 & 0 & 0 & 1 & 0 & 1 \\
\hline Note: EC indicatean & 0 & 0 & 0 & 0 & 0 \\
\hline
\end{tabular}

Note: EC indicates early childhood. Only terms used in at least three different articles were included. Italics indicate a term that was not included as a choice in the online survey (but could have been written in by responden. 


\section{Table 3}

Frequency of Terms for Setting

\begin{tabular}{lcccccc}
\hline & $\begin{array}{c}\text { Total } \\
\text { Across } \\
\text { Articles }\end{array}$ & $\begin{array}{c}\text { Research Practitioner } \\
\text { Articles } \\
(\boldsymbol{n}=\mathbf{2 6})\end{array}$ & $\begin{array}{c}\text { Articles } \\
(\boldsymbol{n}=\mathbf{2 6})\end{array}$ & $\begin{array}{c}\text { Total } \\
\text { Participant } \\
\text { Responses }\end{array}$ & $\begin{array}{c}\text { Phase 2 } \\
\text { responses } \\
(\boldsymbol{n}=\mathbf{2 0})\end{array}$ & $\begin{array}{c}\text { Phase 3 } \\
\text { responses } \\
(\boldsymbol{n}=\mathbf{1 1 2})\end{array}$ \\
\hline Preschool & 15 & 10 & 5 & 54 & 8 & 46 \\
Head Start & 11 & 7 & 4 & 3 & 3 & 0 \\
Kindergarten & 9 & 7 & 2 & 0 & 0 & 0 \\
School & 9 & 7 & 2 & 12 & 4 & 8 \\
EC Program & 8 & 5 & 3 & 34 & 1 & 33 \\
EC & 8 & 6 & 2 & 0 & 0 & 0 \\
Early Educational & 6 & 3 & 3 & 0 & 0 & 0 \\
Setting & & & & & & 0 \\
EC Classroom & 5 & 4 & 1 & 0 & 0 & 0 \\
Prekindergarten & 6 & 4 & 2 & 1 & 1 & 0 \\
EC setting & 3 & 1 & 2 & 0 & 0 & 0 \\
Preschool Classroom & 3 & 1 & 2 & 0 & 0 & 0 \\
Preschool Program & 3 & 3 & 0 & 0 & 0 & 0 \\
Childcare center & 3 & 3 & 0 & 26 & 2 & 24 \\
Program Name & 0 & 0 & 0 & 5 & 5 & 0 \\
Early Head Start & 0 & 0 & 0 & 2 & 2 & 0 \\
EC center & 0 & 0 & 0 & 2 & 2 & 0 \\
Early learning center & 0 & 0 & 0 & 2 & 2 & 0 \\
Christian Preschool & 0 & 0 & 0 & 1 & 1 & 0 \\
Early learning & 0 & 0 & 0 & 1 & 1 & 0 \\
Childcare program & 0 & 0 & 0 & 1 & 1 & 0 \\
Happy program & 0 & 0 & 0 & 1 & 1 & 0 \\
Daycare & 0 & 0 & 0 & 1 & 0 & 1 \\
\hline Note: EC indicates & 0 & 0 & 0 & 0 & 0 \\
\end{tabular}

Note: EC indicates early childhood. Only terms used in at least three different articles were included. Italics indicate a term that was not included as a choice in the online survey.

${ }^{a}$ Some participants listed the actual name of their early childhood program. 


\section{Table 4}

Themes in Phase 2 and 3 Responses

\begin{tabular}{|c|c|c|}
\hline Theme & Definition & Example \\
\hline $\begin{array}{l}\text { Preschool is teaching/ } \\
\text { educating }\end{array}$ & $\begin{array}{l}\text { Actual use of the phrases } \\
\text { (teaching/educating/learning) as well as the idea of } \\
\text { preparing kids for future learning }\end{array}$ & $\begin{array}{l}\text { "It's strictly teaching, modeling what is to be } \\
\text { expected when they go to school... It is more } \\
\text { teaching in the preschool than the day care." }\end{array}$ \\
\hline Curriculum & $\begin{array}{l}\text { The idea that there is a curriculum or a structured set } \\
\text { of activities that are used }\end{array}$ & "There is a little more advanced curriculum" \\
\hline Planning & $\begin{array}{l}\text { The idea that there is intentional planning involved } \\
\text { in their work. }\end{array}$ & "... have lesson plans" \\
\hline Expertise & $\begin{array}{l}\text { The idea that these teachers have special knowledge } \\
\text { or training of some sort. }\end{array}$ & "I have the knowledge to back it up" - \\
\hline $\begin{array}{l}\text { Important role early } \\
\text { childhood plays in } \\
\text { children's development }\end{array}$ & $\begin{array}{l}\text { The idea that early childhood is a critical time for } \\
\text { learning and that the work participants are doing is } \\
\text { important for that reason. }\end{array}$ & $\begin{array}{l}\text { "Early childhood is so important... The first five } \\
\text { years of life are so vital for success later on." }\end{array}$ \\
\hline $\begin{array}{l}\text { Not a daycare, provider, } \\
\text { babysitter }\end{array}$ & $\begin{array}{l}\text { When the participant explicitly says that they do not } \\
\text { work in/at a daycare or they are not a daycare } \\
\text { provider or they are not a babysitter. }\end{array}$ & $\begin{array}{l}\text { "I'm not a daycare" / "...we teach the kids every } \\
\text { day we are not babysitters." }\end{array}$ \\
\hline No difference or $N / A$ & $\begin{array}{l}\text { Participants' responses indicate that they do } \\
\text { not perceive a difference in the terms that are used. }\end{array}$ & "n/a" / "no difference" \\
\hline Funding & $\begin{array}{l}\text { Participants describe funding as a reason for } \\
\text { differences among terms. }\end{array}$ & $\begin{array}{l}\text { "Differences come from... funding from each } \\
\text { different program" }\end{array}$ \\
\hline Professionalism & $\begin{array}{l}\text { Participants explicitly use the word "professional" to } \\
\text { describe differences in terms. }\end{array}$ & $\begin{array}{l}\text { "early childhood programs and preschool convey } \\
\text { the education and professionalism of the area of } \\
\text { focus" }\end{array}$ \\
\hline Quality & $\begin{array}{l}\text { Participants explicitly use the word } \\
\text { "quality" to describe differences in terms. }\end{array}$ & $\begin{array}{l}\text { "I feel that quality childcare programs refer to } \\
\text { themselves as childcare programs." }\end{array}$ \\
\hline
\end{tabular}

Note: Italics indicate themes that were unique to the Phase 3 survey responses. 